\title{
Research Utilizing of Omani Bio-Waste in Carbon Based Nanocomposite Materials for Wastewater Treatment
}

\author{
Khadija Al Balushi \\ International Maritime College, Oman \\ khadijalbalushi8@gmail.com
}

\author{
Dr. Meisam Valizadeh Kiamahalleh \\ International Maritime College Oman
}

\begin{abstract}
Date palm seeds (DPS) is the main biomass sources in Oman, and it constitutes 80 wt\% of all the fruits crops produced and $50 \mathrm{wt} \%$ of the total agriculture area in the country is assessed for its potential for preparation of activated carbon (AC). One of the important agent for selective organic contaminant elimination and amphiphilic agent for water uptake is AC based hydrogels. However, AC application fields are limited due its high cost. In present work, AC starch hydrogel (ACSH) is produced from locally available DPS by utilizing $\mathrm{KOH}$ as an activating agent, carbonized and finally incorporated into starch hydrogel to construct solid stand-alone adsorbent for organic dye molecules. Based on SEM the structural characteristics were evaluated, the adsorption behavior was studied to verify its efficiency in the elimination of methylene blue (MB) with regards to the impregnation ratio (IR), time of activation, and temperature of activation process variables. The highest adsorption capacity of ACSH was found $28.13 \mu \mathrm{g}$ of dye/g of adsorbent which was $225 \%$ enhancement compared to that of the plain starch hydrogel. The process influence variables on the AC adsorption characteristics were analyzed with the help of the response surface methodology (RSM) and analysis of variance (ANOVA), which finds the important parameters as well as significance of the experiment model. The identified experimental optimum conditions are time for activation is $58 \mathrm{~min}$, temperature for activation is $400^{\circ} \mathrm{C}$ and IR of 3 . Furthermore, the kinetic studies analyzed data well fitted to the pseudo-first order dynamic equation. The outcomes confirmed that ACSH to be an effective method for preparing highly porous AC from DPS.
\end{abstract}

Keywords: Date palm seeds, Activated carbon, Methylene Blue, Hydrogels, Adsorption.

\begin{tabular}{ll}
\multicolumn{2}{l}{ Nomenclature } \\
\hline Abbreviations & Descriptions \\
\hline DPS & Date palm seeds \\
AC & activated carbon \\
IR & impregnation ratio \\
MB & methylene blue \\
ANOVA & analysis of variance \\
DOE & design of experiment \\
RSM & response surface methodology \\
CCD & central composite design \\
CCFD & central composite face centered design \\
\hline
\end{tabular}

\section{Introduction}

Due to stringent environmental regulations and awareness about the environment, wastewater treatment has always been a key aspect of research. Water is essential component for any country's financial prosperity [4] [5]. In the near future, the economic importance of water is expected to be increased with economic global growth [8]. In the recent days, water pollution is the major problem, which comes into more attention [11] [12]. The rising of toxic compounds (i.e. intense metals and natural compounds) and diverse dangerous into water did not pressure the life of marine, and the ecological society [10].

The important issues are the water contamination and its treatment [47]. Hence, numerous methods were developed such as precipitation, ion exchange, coagulation, flocculation, crystallization, photodegradation, etc. [56]. The recent drift in this sector is the adsorption techniques because of its 
simplicity, maximum efficiency, and minimum cost. Various resources are used in this drift including graphene [27] [29][39][40] carbon nanotubes carbonaceous nanofiber membranes, mesoporous carbon and carbon nanofiber aerogels [7] [9] [13]. The efficiency of the removal of dyes pollutants of the above carbon materials is high [30] [31] [32][41]. Anyhow, most of the production methods were costly, difficult in large production scale and extensive energy consuming due to non-renewable resources, difficult preparation and the fabrication process is very complicated [15] [16].

The bio-wastes are one of the significant feedstock the use of bio-wastes as precursor materials to produce $\mathrm{AC}$ has become one of hot topics and gained much attention mainly because of their low cost, friendly nature with the environment and renewable [28]. In the last years, the total publications related in conversion of bio-waste to AC have significantly increased. At present, these bio-wastes are not being to use for any other applications and there are mostly dumped as solid waste [48]. That is why it's very essential and necessary to find out some applications for these bio-wastes as they can contribute to real environmental problems [52]. This project aims to produce a low cost alternative adsorbent from Omani date seeds [2] [3]. There are different bio-wastes available in Oman such as Date seeds, Mango and Banana peels however, among all these bio-wastes date seeds have proved to be the suitable one due to its excellent nature structure and less ash content [14]. The application of low-cost adsorbents obtained from bio-waste material, which is used instead of costly conventional methods of eliminating contaminants from wastewater. It is proven that carbon-based material [42] [43] [44] is considered the ideal material to remedy water and has been shown to be a promising material [17].

Industrial wastewater [21] has different organic and inorganic compounds which are characterized as mutagenic, toxic and carcinogenic which have the potential to cause adverse effect on man when persist in the environment, vegetation and marine life [53]. The intense metals [38] available in the industrial devastate water such as $\mathrm{Cd}, \mathrm{Pb}, \mathrm{Zn}, \mathrm{Cr}$ and $\mathrm{Ni}$ they are the most toxic and perilous materials among the other toxic materials from the chemical and allied industries [55] [33] [34] [35] [36]. In the recent years, carbon-based nanomaterials [37] and $\mathrm{AC}$ are used to remove various pollutants from the water [22] [23], because of its flexibility [6].

$\mathrm{AC}$ has great potential as novel type of adsorbent of heavy metals and organic compounds such as zinc, cadmium, lead, copper, nickel, as well as fluoride and radioactive nuclides. AC is a one of the members of carbon fibers [45] [46] and composite of graphene sheet [50], which came from the organic parent sources, but various manufacturing and carbonization methods [19] [20]. It has the natural characteristics that influence the metal adsorption such as surface area, chemical nature of their surface and distribution of pore size. The interaction is due to the strong binding energy of van der waals for the molecular adsorbents [49]. From different raw materials AC can be produced which can be turned incredibly versatile product that can be easily created and produced in many different areas depending on the availability of the raw material [54] [18].

It has to be synthesized it does not just happen. The porosity of carbon [51] is prepared by carbonization, but for most applications are not sufficiently developed it needs several methods involving widening of existing porosity, creation of further porosity, changing the porosities surfaces and changing the process of carbonization itself. The activation can be physical or chemical, in physical activation the steam or carbon dioxide [59] [60] or the combination of these two gases are used with activation temperatures typically range from $700^{\circ} \mathrm{C}$ to $1000^{\circ} \mathrm{C}$ while in chemical activation certain chemicals are used including strong acids, alcohols and bases and heated from $400^{\circ} \mathrm{C}$ to $800^{\circ} \mathrm{C}$ [24] [25]. The $\mathrm{KOH}$ is used to create vastly microporous carbons, which gives maximum adsorption capacity than the activating agents such as zinc chloride and phosphoric acid [57] [58].The main objective of this research work to develop and produce AC from very less cost alternatives which could filter out water contaminants, which is considered as a convenient method in water remediation filed. Furthermore, this research aims to find out the highest adsorption capacity of AC.

\section{Experimental Methods}

\subsection{Preparation of DPS}

DPS is produced from the local agricultural farms in Al Buraimi, Oman. $500 \mathrm{~g}$ of date seeds prepared and cleaned again and again with distilled water is used to eliminate the foreign materials and then dehydrated in oven at $80^{\circ} \mathrm{C}$ for two nights. When date seeds getting all crispy, a grinder is used to produce powdered date. The powder material saved in airtight container for future experiment. 


\subsection{Activation Process}

A strong base is used to activate the date seeds powder which is $\mathrm{KOH}$. $60 \mathrm{~g}$ of date seeds powder separated equally in three samples and each one of them having different amount of $\mathrm{KOH}$ and distilled water at an IR of 1-5. Sample 1X, 3X and 5X have (20g KOH:20g DPS), (60g KOH:20g DPS), and (100g $\mathrm{KOH}: 20 \mathrm{~g}$ DPS), respectively. Also, make sure that the $\mathrm{KOH}$ is soaked completely, for $8 \mathrm{~h}$ then filtered to remove all the water using centrifuge device. Then, the mixture is placed in the oven at $80^{\circ} \mathrm{C}$ all night upon completion of the dryness, the samples are then crushed into powder.

\subsection{Carbonization}

$5 \mathrm{~g}$ of the dried and impregnated date seeds powder was carbonized in a reactor at a specific heat of $400^{\circ} \mathrm{C}-700^{\circ} \mathrm{C}$ for $30-120$ min of activation time with continues nitrogen flow (nitrogen flow of 150 $\mathrm{ml} / \mathrm{min}$ ). The aim to carry out the whole heating process with a constant flow of nitrogen is to make sure removal of oxygen from the system and to maintain an inert atmosphere inside the reactor in addition to prevent burning and removal of all volatiles produced during the process. The carbonized crushed samples were cooled to the normal temperature. Upon completion of 20 runs, the carbonized samples were washed with hydrochloric acid $(\mathrm{HCl})$ aqueous solution to eliminate all ash exits in the materials, and then wash with the distilled water, when to $\mathrm{pH}$ reach to neutral. Finally, the AC samples were placed in oven at $80^{\circ} \mathrm{C}$ for $24 \mathrm{~h}$ to make sure a total dryness.

\subsection{Paration of ACSH}

$3.5 \mathrm{~g}$ of starch was assorted with $25 \mathrm{ml}$ water and $16 \mathrm{mg}$ of $\mathrm{AC}$ were added with $1.5 \mathrm{ml}$ of glycerol to connect them together. After that, the mixture was mixed at $600 \mathrm{rpm}$ for 5 minutes to insure entire dispersion, then immediately the mixture was sonicated for 15 minutes the power adjusted to $30 \%$ for dispersion and gelation process. As the gel started forming, it was poured into a tube and cooled at $4{ }^{\circ} \mathrm{C}$. Each hydrogel sample dried by using the freezer drying to keep the nanostructure of it before undergoing through characterization.

\section{Experimental Design and Statistical Analysis}

The statistical DOE is a useful procedure for saving money and time achieved by reducing the amount of tests required to learn the multi-variable phenomenon. Its highly helpful in screening likely variables for cases involving second-order models. Furthermore, DOE calculate so many interactions between the main variables as well as their effects on a process response. The group of statistical and mathematical methods used for generating the three-dimensional plots and showing statistical analyzes of how process variables influence responses is called the RSM. The most popular RSM design used for the experimental data analysis is called CCD. The process parameters (variables) are reaction temperature (A), IR (B), and reaction time $(\mathrm{C})$, while the reply selected were porous carbon yield (\%) and MB adsorption Capacity. The statistical DOE by CCFD method for preparation of AC from DPS suggested 20 runs and five were repeated for the process parameters of optimization. The low levels and high levels of factors are shown in Table 1, in which the high level corresponds to code +1 , the bottom level to code -1 and the center level to code zero. The coded level and actual value of these variables have been generated and tabulated by the DOE analysis in which the value of -1 and 1 shows the minimum and maximum range of each variable and 0 is the center point. The resuls obtained will then be used to elucidate regression model fitting and the statistical analysis helps to ensure the adequacy of the this model in representing results. The mathematical relationship relating variables to the responses can be calculated by the general quadratic equation model as follows:

$$
\mathrm{Y}_{\mathrm{i}}=\beta_{0}+\sum_{\mathrm{i}=1}^{\mathrm{k}} \beta_{\mathrm{i}} \mathrm{X}_{\mathrm{i}}+\sum_{\mathrm{i}=1}^{\mathrm{k}} \beta_{\mathrm{ii}} \mathrm{X}_{\mathrm{i}}^{2}+\sum_{\mathrm{i}\langle\mathrm{j}}^{\mathrm{k}} \beta_{\mathrm{ij}} \mathrm{X}_{\mathrm{i}} \mathrm{X}_{\mathrm{j}}+\varepsilon
$$

where Yi represents the expected outcome (dependent variable), $\mathrm{Xi}$ and $\mathrm{XiXj}$, respectively, and these variables are independent and their interactions which influence the acknowledgement variable Yi; 80 represents the stable coefficient, Bi, Bii and Bij represent the linear coefficient, coefficient for quadratic and effects for interacttion, respectively. $\varepsilon$ is the standard error. There are three variables are involved, hence, $\mathrm{k}$ is 3 in this study. The outcome of the experimentations are evaluated with the help of statistical computing software minitube using the equation model and the ANOVA. 
Table 1 High and low levels of factors

\begin{tabular}{lccccc}
\hline \multicolumn{1}{c}{ Variable } & Notation & Unit & \multicolumn{2}{c}{ Coded levels of the variables } \\
\hline Reaction Temperature & (A) & ${ }^{\circ} \mathrm{C}$ & $\mathbf{- 1}$ & $\mathbf{0}$ & $\mathbf{1}$ \\
KOH/biomass & (B) & gr & 400 & 550 & 700 \\
Reaction Time & (C) & min & 1 & 3 & 5 \\
\hline
\end{tabular}

\section{Structural Characteristic of AC}

$\mathrm{AC}$ are remarkably complex in terms of the shape, size, inconstancy of their porosity and the porous carbon's structural heterogeneity acts a significant role in process of adsorption, and for the description of this property there are various techniques were formed, developed and implemented. SEM images explicate the morphology of the material's surface to ensure the scenarios made on the adsorption behaviors in this research. All the tested samples dried by freeze dryer where the pressure is under vacuum while the temperature should be $-80^{\circ} \mathrm{C}$ To get a good quality image, the samples must be on a conductive material and coated by sputtering technique in order to avoid repulsing electrons and getting a blurry image for this research a platinum coating was used.

\section{Results and discussion}

Table 2 shows the Full design matrixes including the responses of experimentation results. Last five runs were repeated to the determination of experimental error. The AC yield found to vary from 15.73 to $82.56 \%$ whereas the MB adsorption capacity varies from 13.23 to $28.12 \mu \mathrm{g} / \mathrm{g}$.

Adsorption experiments were brought out in UV-VIS spectroscopy using MB. The adsorption capacity measurement of ACSH was done by immersing $0.65 \mathrm{~g}$ of each hydrogel into the bottom of cuvette filled with $3 \mathrm{ml}$ of dye with the concentration of $26.66 \mu \mathrm{M}$. The UV-Visible light absorbance of MB with wavelengths of $664 \mathrm{~nm}$ was recorded continuously for $24 \mathrm{hr}$ by a UV-Visible spectrometer. The adsorption capacity of MB was studied using the formula as follows:

$$
q e=\frac{\left(c_{0}-c_{e}\right) v}{w}
$$

Where, $q(e)$ represents the adsorption for equilibrium $(\mu \mathrm{g} / \mathrm{g})$, Co indicates the MB solution's first concentration $(\mu \mathrm{g} / \mathrm{L})$, Ce represents the concentration of equilibrium $(\mu \mathrm{g} / \mathrm{L})$, V indicates the MB solution's volume possessed for the experiment of adsorption (L), and W represents the adsorbent weight in (g).

Table 2 Experimental data

\begin{tabular}{|c|c|c|c|c|c|c|}
\hline \multirow[b]{2}{*}{ Run } & \multirow[b]{2}{*}{ Variable Type } & \multicolumn{3}{|c|}{ Variables } & \multirow{2}{*}{$\begin{array}{l}\text { Response } \\
\text { AC Yield (\%) }\end{array}$} & \multirow{2}{*}{$\begin{array}{l}\text { Response } \\
\text { MB adsorption } \\
\text { Capacity }(\mu \mathrm{g} / \mathrm{g})\end{array}$} \\
\hline & & $\mathrm{A},\left({ }^{\circ} \mathrm{C}\right)$ & $\mathrm{B},(\mathrm{gr} / \mathrm{gr})$ & $\mathrm{C},(\min )$ & & \\
\hline 1 & Factorial & 400 & 1 & 30 & 41.24 & 14.2024 \\
\hline 2 & Factorial & 700 & 1 & 30 & 50.76 & 16.5840 \\
\hline 3 & Factorial & 400 & 5 & 30 & 76.68 & 19.6621 \\
\hline 4 & Factorial & 700 & 5 & 30 & 21.44 & 19.2916 \\
\hline 5 & Factorial & 400 & 1 & 120 & 21.93 & 19.8241 \\
\hline 6 & Factorial & 700 & 1 & 120 & 34.54 & 14.6739 \\
\hline 7 & Factorial & 400 & 5 & 120 & 80.12 & 14.0509 \\
\hline 8 & Factorial & 700 & 5 & 120 & 58.13 & 17.5642 \\
\hline 9 & Axial & 400 & 3 & 75 & 82.56 & 17.6087 \\
\hline 10 & Axial & 700 & 3 & 75 & 67.62 & 28.1286 \\
\hline 11 & Axial & 550 & 1 & 75 & 31.86 & 18.9147 \\
\hline 12 & Axial & 550 & 5 & 75 & 44.47 & 21.3166 \\
\hline 13 & Axial & 550 & 3 & 30 & 15.73 & 13.2394 \\
\hline 14 & Axial & 550 & 3 & 120 & 53.12 & 27.5772 \\
\hline 15 & Center & 550 & 3 & 75 & 63.18 & 21.4500 \\
\hline 16 & Center & 550 & 3 & 75 & 68.54 & 21.1250 \\
\hline 17 & Center & 550 & 3 & 75 & 70.14 & 21.5738 \\
\hline 18 & Center & 550 & 3 & 75 & 61.79 & 21.9982 \\
\hline 19 & Center & 550 & 3 & 75 & 67.90 & 21.6077 \\
\hline 20 & Centre & 550 & 3 & 75 & 46.39 & 21.4519 \\
\hline
\end{tabular}




\subsection{ACSH Adsorption Study}

20 experiments were conducted with the variables are in activation time, IR, and activation temperature, for adsorption study of MB. In order to compare the adsorption capacity of the AC hydrogels, figures below exhibits dye adsorption profiles over $24 \mathrm{hr}$ Fig. 1 shows MB adsorption profile at highest and lowest activation temperature, the MB demonstrated a great kinetics of adsorption in the first hours and reached to its maximum capacity by filling all the available pores in the hydrogel. The MB was adsorbed because of the $\Pi-\Pi$ stacking and the bonding of hydrogen interactions among dye molecules along with ACSH species. At high activation temperature the adsorption capacity increased gradually reaching to high range of adsorption. Fig. 2 shows ACSH image before and after MB adsorption (a\& b) at activation temperature $400{ }^{\circ} \mathrm{C} \mathrm{(c} \mathrm{\&} \mathrm{d)} \mathrm{at} \mathrm{activation} \mathrm{temperature} 700{ }^{\circ} \mathrm{C}$. In Fig. 3 the MB uptake was higher for high activation time. At high IR as is shown in Fig. $4 \mathrm{MB}$ uptake was higher in the first hours compare it too low IR then gradually decreased till it reaches to equilibrium. When the activation temperature and IR had the maximum values within the range of study, then the observed MB adsorption was high, which shows the improvement in pore size's suitability to MB molecules accommodation. That means the improvement in the activation temperature and IR leads to reducing the yield which is a possible determination of improvement in the porosity because of new pores creation or to growth of exiting pores. Hence, the improvement in MB leads to the improvement in activation temperature and IR.

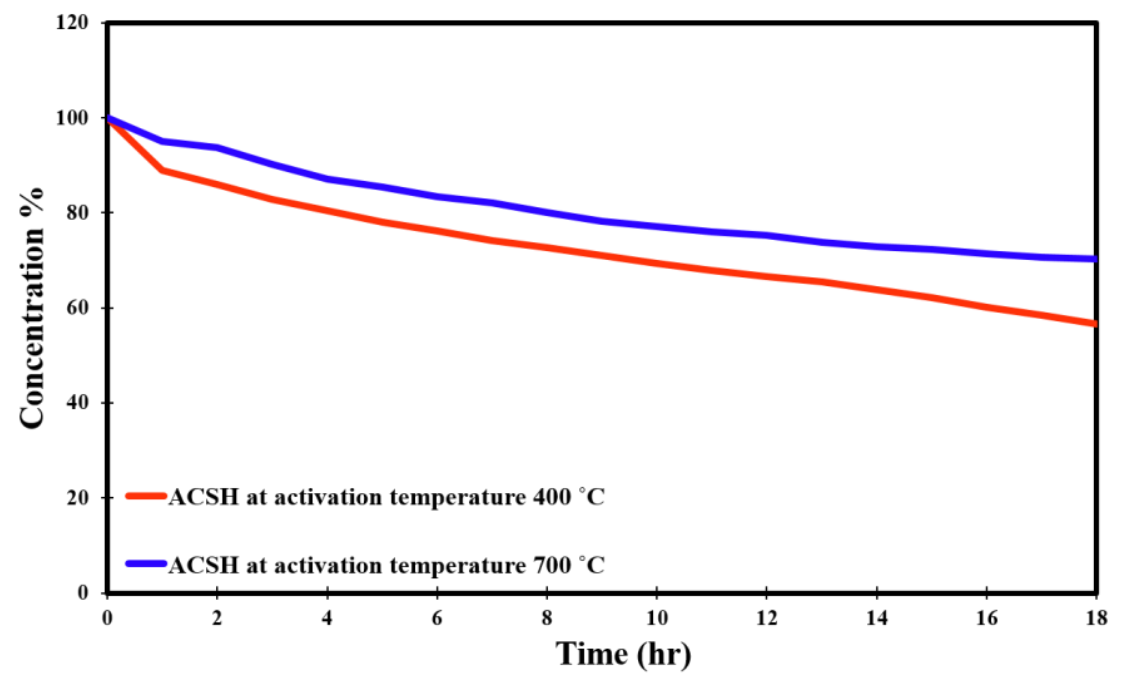

Fig. 1 UV-Vis spectroscopy pattern for ACSH for MB adsorption at different activation temperature.
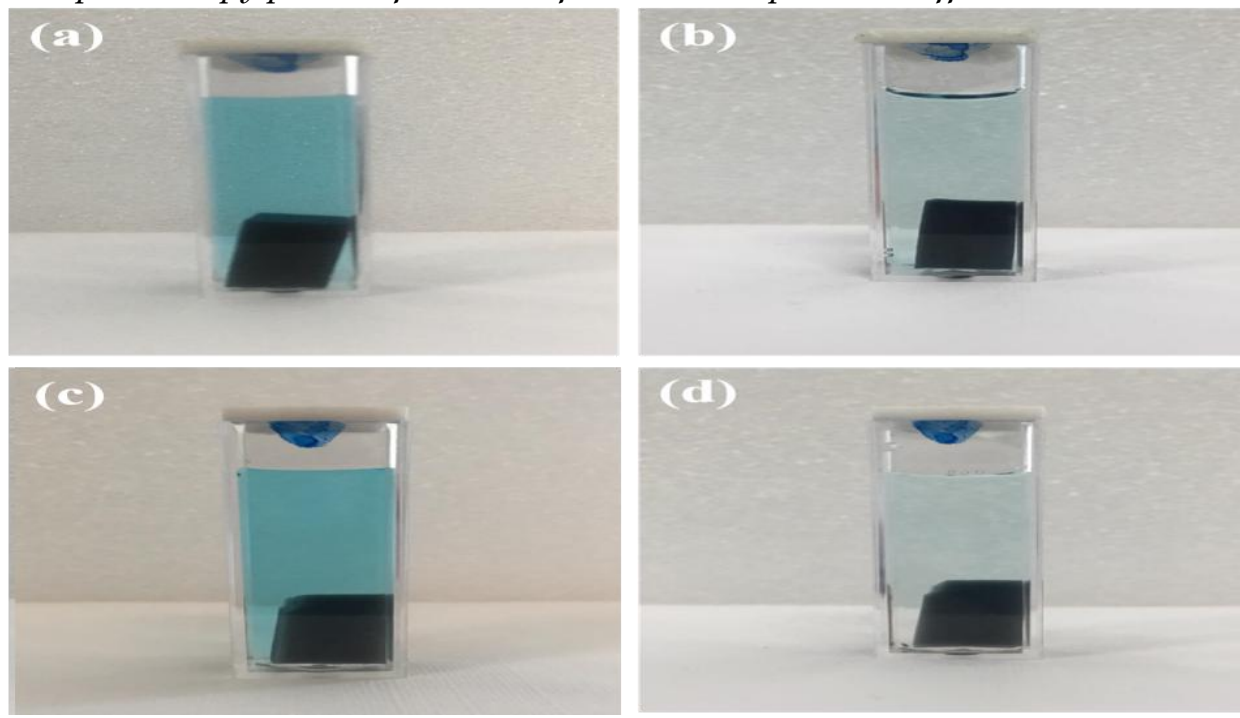

Fig. 2 ACSH image before and after $M B$ adsorption ( $a \& b)$ at activation temperature $400{ }^{\circ} \mathrm{C}(c \& d)$ at activation temperature $700{ }^{\circ} \mathrm{C}$. 


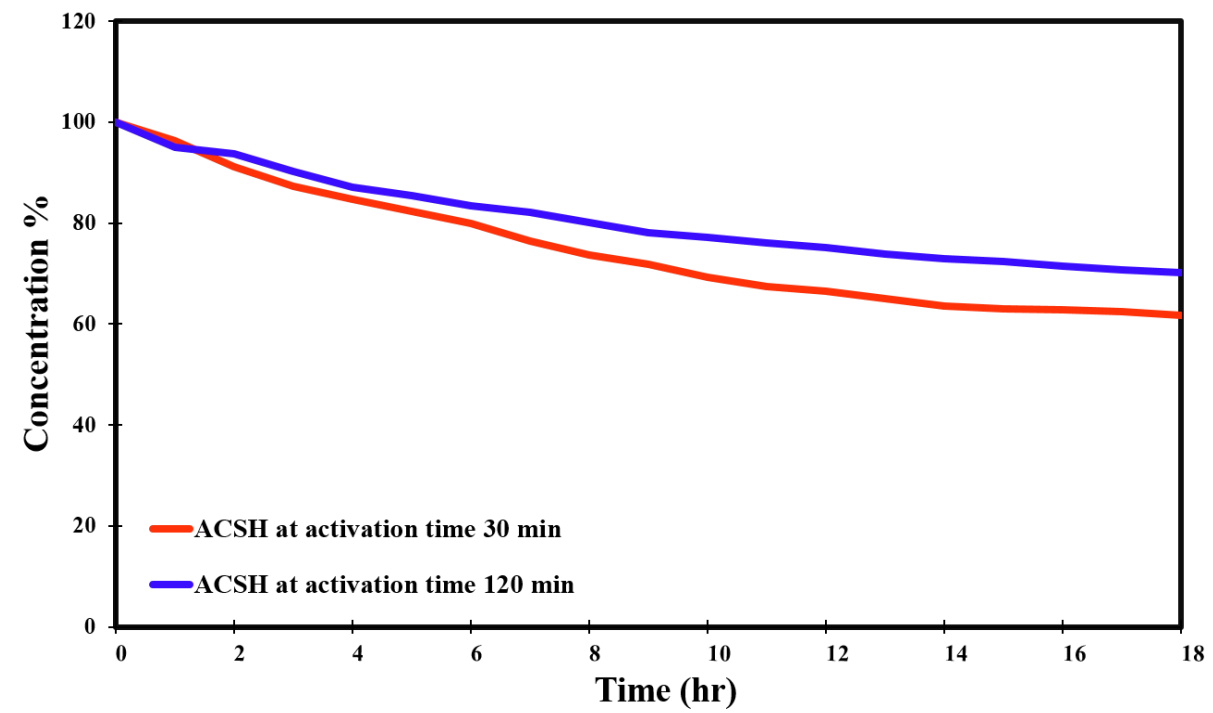

Fig. $3 U V$-Vis spectroscopy pattern for ACSH for MB adsorption at different activation time.

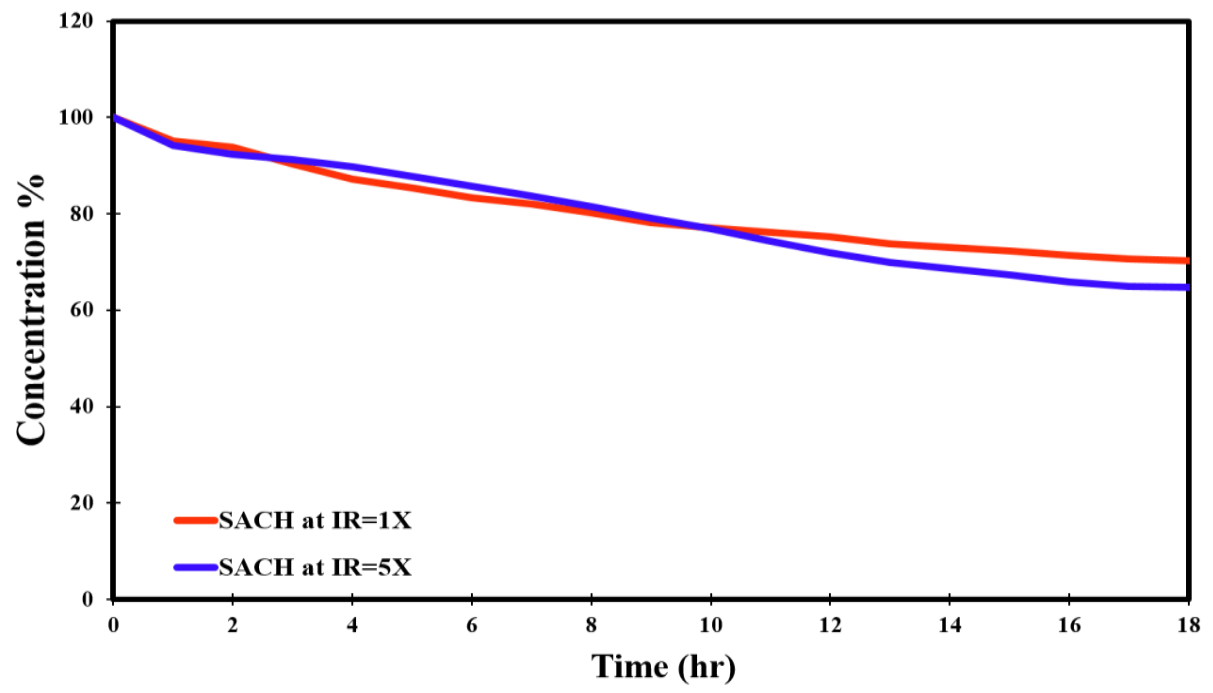

Fig. $4 U V$-Vis spectroscopy pattern for ACSH for MB adsorption at different IR.

\subsection{Day Adsorption Kinematics}

The occurrence of adsorption process in porous media (AC hydrogels film in our case) is not instant, but it may pass through some steps. Firstly, the dye molecules transport in the solution; the second step is the external diffusion where the dye molecules surround the hydrogel; then internal diffusion is the third step in which the dye diffuses within the liquid inside the pores of the hydrogel. At the end, the molecules will attempt to penetrate inside the pore and accommodate on the surface by, physisorption, ion exchange and precipitation Kinetic modeling is not only used for the sorption rates estimation but also helps to appropriate rate expressions quality of probable response mechanisms. When film diffusion is rate controlling (simple sorption or physisorption), the equation for pseudo-first order rate is applied which is represented as follows:

$$
\log \left(q_{e}-q_{t}\right)=\log q_{e}-\frac{k_{1}}{2.303} t
$$

where, qe and qt represent the dye adsorbed concentration at a specific time and at equilibrium and rate constant of the first order is $\mathrm{k} 1$ (min-1). The plot's slope value of log (qe-qt) Vs time was used to calculate the rate constant first order. The plot was also used to calculate the coefficient of correlation (R2) (Suresh et al., 2014).

The pseudo second order model with the assumption that chemical sorption or chemisorption is expressed as follows: 


$$
\frac{t}{q_{t}}=\frac{1}{k_{2} q_{e}^{2}}+\frac{t}{q_{e}}
$$

where, $\mathrm{k} 2$ (g $\mu \mathrm{g}-1 \mathrm{~min}-0.5$ ) represents the rate constant of second order data for experimentation, t/qt were marked with respect to the time ( $\mathrm{min}$ ) and second order pseudo constant K2was calculated. The adsorption capacity of equilibrium qe of SACH from the slope and intercept value. Also, by using the plot the coefficient of correlation (R2) was calculated, which decides which kinetic sample suit for the process of adsorption (Suresh et al., 2014).

Table 4 is associated to the mechanism and kinetics of dye adsorption onto ACSH. Comparing between the two kinetic models, the R2 pseudo-first-order values were greater than the pseudo-secondorder, which indicates to the rate-controlling step of the adsorption operation is physisorprion. Figures below show the adsorption capacity of the hydrogels towards MB at two different kinetic models.

\subsection{Day Adsorption Mechanism}

In order to better understand the dye mechanism of adsorption and to evaluate the data of adsorption for ACSH Langmuir and Freundlich models were utilized to fit the experimental value in the first cycle of adsorption. The Langmuir isotherm assumes the monolayer sorbate adsorption occurring on a uniform surface, whereas the Freundlich model considers the sorbate to form multilayer with a various energetic distribution of the lively sites. The equations of Freundlich and linear Langmuir and are expressed in Eq 5 and 6 , respectively [x26].

$$
\begin{aligned}
& \frac{t}{q_{t}}=\frac{1}{K q_{e}}+\frac{t}{q_{e}} \\
& \operatorname{In}\left(q_{t}\right)=\ln \left(K_{f}\right)+\left(\frac{1}{n}\right) \ln (t)
\end{aligned}
$$

The Freundlich and Langmuir parameters of isotherm which were evaluated by using the slope and intercept of the plots are provided in Table 3. Hence, the linear Freundlich model with regression coefficients of R2: 0.9988, 0.9827, 0.9821, 0.9827, 0.9827, and 0.986 for ACSH fitted the experimental data much better than Langmuir whose R2 are: 0.9811, 0.9292, 0.9811, 0.0207, 0.2224 and 0.9811. These results furthermore, suggest a multilayer adsorption profile for the ACSH on the heterogeneous surface

\begin{tabular}{|c|c|c|}
\hline \multirow[t]{2}{*}{ Sample } & Langmuir & Freundlich \\
\hline & $\mathbf{R}^{2}$ & $\mathbf{R}^{2}$ \\
\hline $\mathrm{ACSH}-700{ }^{\circ} \mathrm{C}$ & 0.9811 & 0.9827 \\
\hline $\mathrm{ACSH}-400{ }^{\circ} \mathrm{C}$ & 0.9292 & 0.9988 \\
\hline ACSH-120 min & 0.9811 & 0.9827 \\
\hline ACSH-30 min & 0.0207 & 0.896 \\
\hline ACSH-IR 5 & 0.2224 & 0.9821 \\
\hline ACSH-IR 1 & 0.9811 & 0.9827 \\
\hline
\end{tabular}
of the hydrogels.

Table $3 R^{2}$ values of the Freundlich and Langmuir models of ACSH.

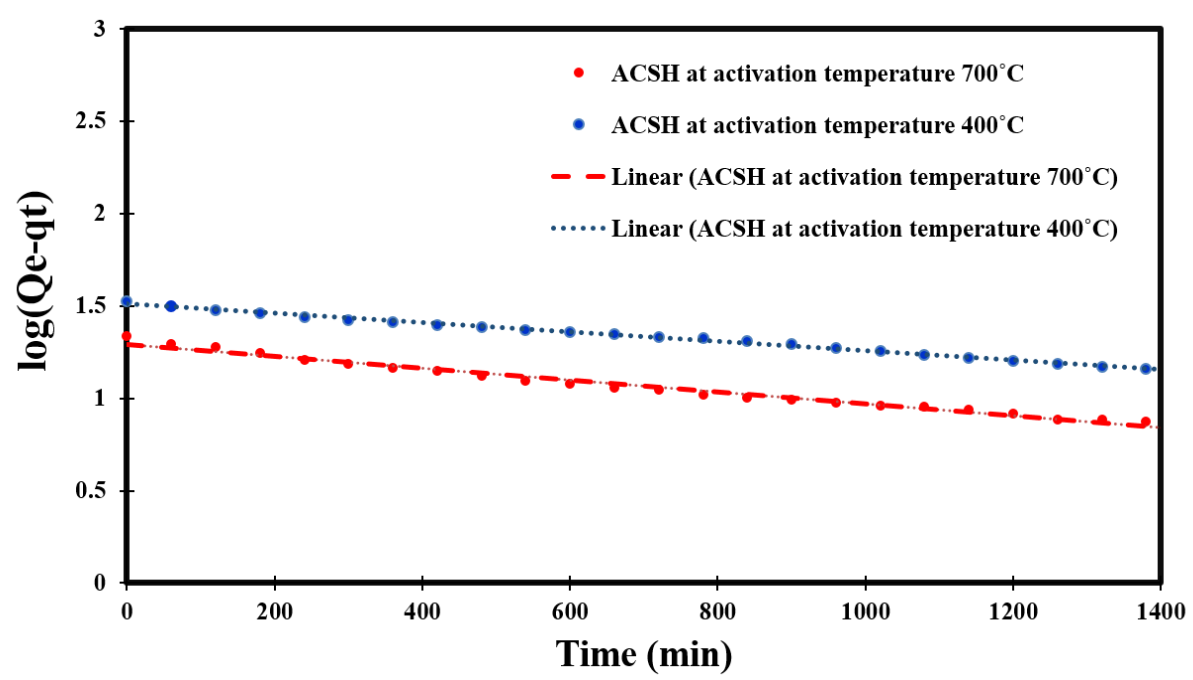

Fig.5 Pseudo first order for ACSH at different temperatures. 


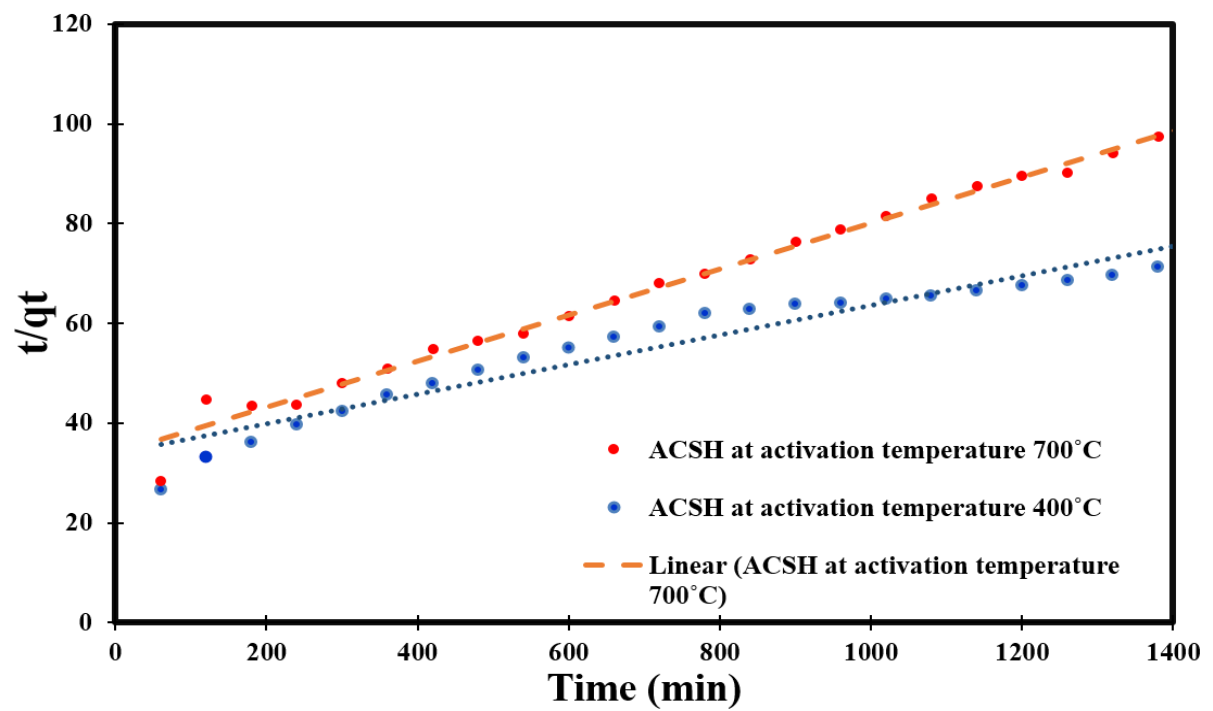

Fig.6 Pseudo second order for ACSH at different temperatures.

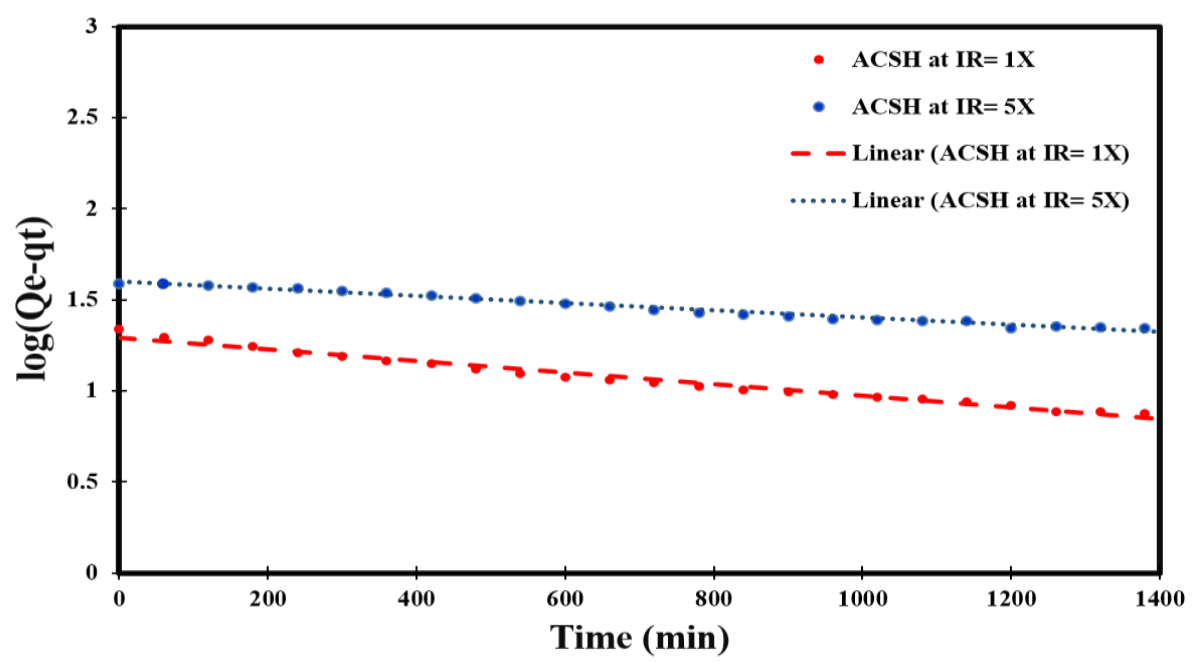

Fig. 7 Pseudo first order for ACSH at different IR.

Table 4 Rate constant of different kinetics models for ACSH.

\begin{tabular}{|c|c|c|c|c|c|c|}
\hline \multirow[t]{2}{*}{ Sample } & \multicolumn{3}{|c|}{ Pseudo-first-order model } & \multicolumn{3}{|c|}{ Pseudo-second-order model } \\
\hline & $K_{1}$ & qe & $\mathbf{R}^{2}$ & $K_{2}$ & qe & $\mathbf{R}^{2}$ \\
\hline $\mathrm{ACSH}-700{ }^{\circ} \mathrm{C}$ & 0.00073 & 19.5433 & 0.9837 & $6.269 \mathrm{E}-05$ & 21.6864 & 0.9811 \\
\hline $\mathrm{ACSH}-400{ }^{\circ} \mathrm{C}$ & 0.00058 & 32.4414 & 0.9962 & $2.488 \mathrm{E}-05$ & 33.7112 & 0.9292 \\
\hline ACSH-120 min & 0.00073 & 19.5433 & 0.9837 & $6.269 \mathrm{E}-05$ & 21.6864 & 0.9811 \\
\hline ACSH-30 min & 0.00012 & 245.019 & 0.7675 & $4.535 \mathrm{E}-07$ & 240.906 & 0.0207 \\
\hline ACSH-IR 5 & 0.00045 & 48.5050 & 0.9855 & 5.933E-06 & 38.8025 & 0.2224 \\
\hline ACSH-IR 1 & 0.00073 & 19.5433 & 0.9837 & $6.269 \mathrm{E}-05$ & 21.6864 & 0.9811 \\
\hline
\end{tabular}




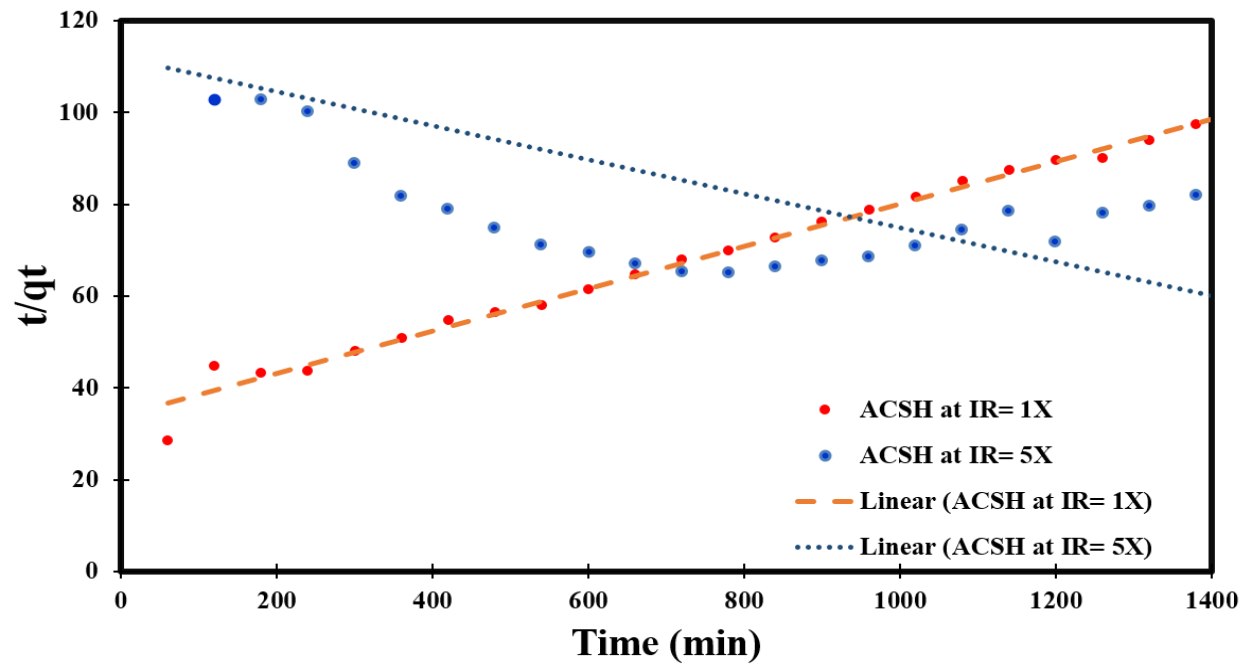

Fig. 8 Pseudo second order for ACSH at different IR.

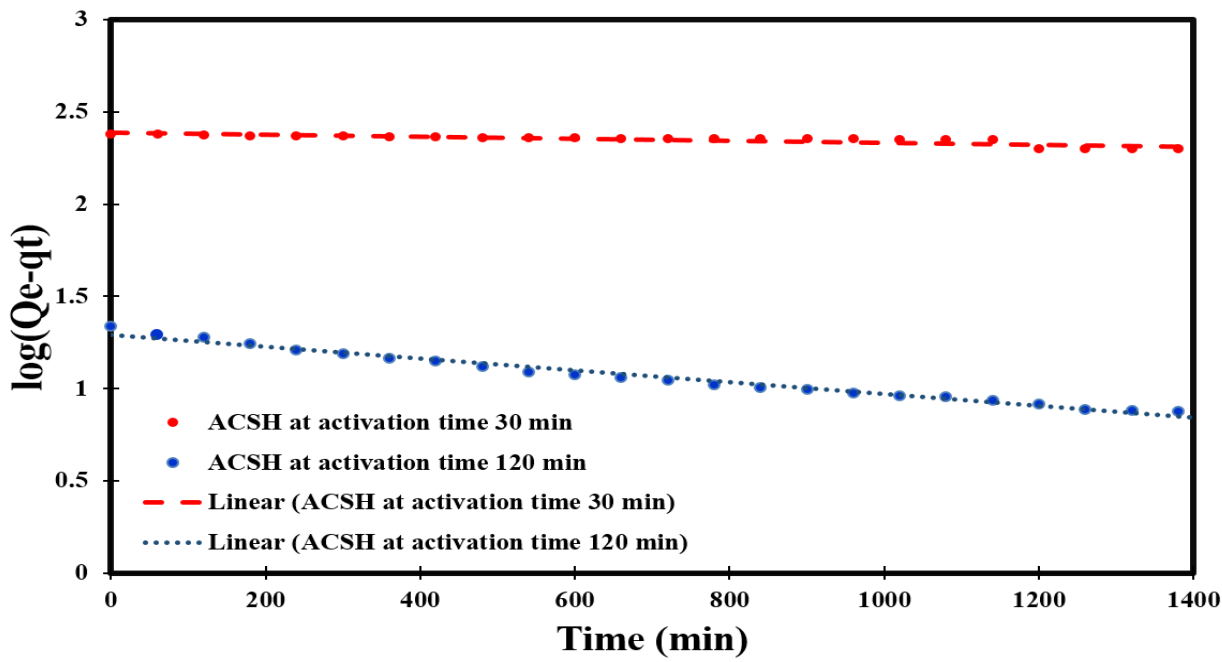

Fig.9 Pseudo first order for ACSH at different time

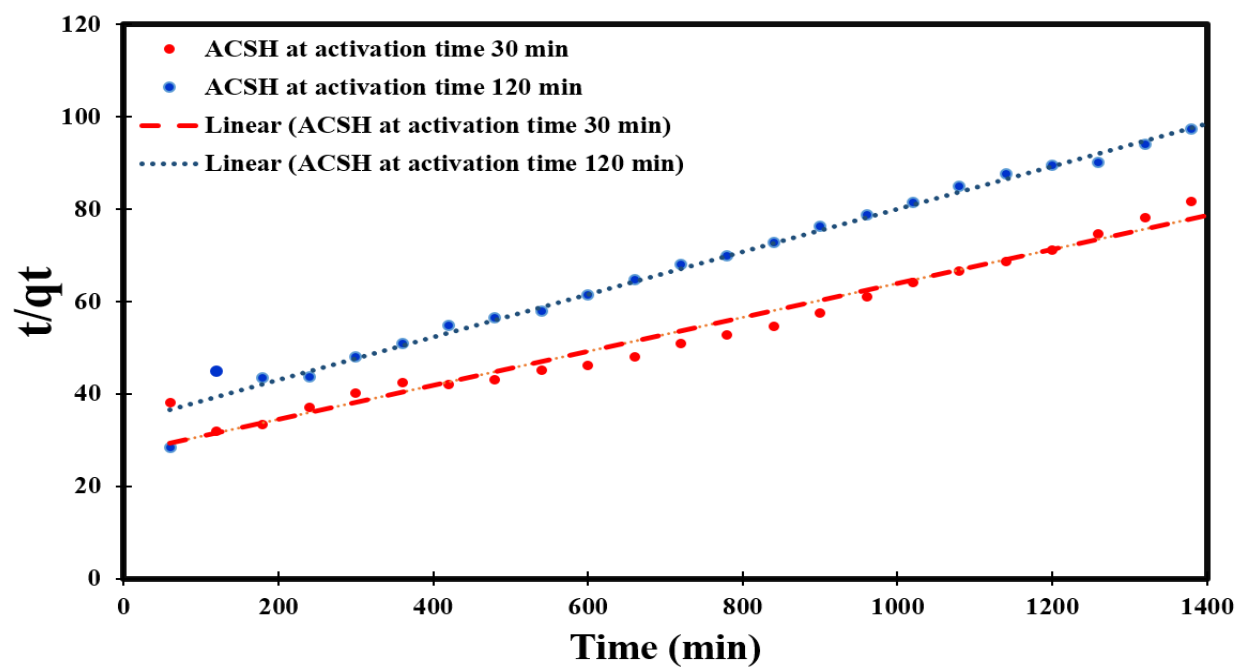

Fig.10 Pseudo second order for ACSH at different time. 
Table 5 ANOVA for $M B$ adsorption capacity of $A C$

\begin{tabular}{|c|c|c|c|c|c|c|}
\hline Source & $\begin{array}{l}\text { Sum of } \\
\text { Squares }\end{array}$ & df & $\begin{array}{l}\text { Mean } \\
\text { Squares }\end{array}$ & $\begin{array}{l}\text { F } \\
\text { Value }\end{array}$ & $\begin{array}{l}\text { p-value } \\
\text { Prob }>\text { F }\end{array}$ & Model \\
\hline Model & 291.29 & 9 & 32.37 & 24.23 & 0.0001 & significant \\
\hline A-Temperature & 55.33 & 1 & 55.33 & 41.43 & 0.0001 & \\
\hline C-Reaction time & 102.79 & 1 & 102.79 & 76.96 & 0.0001 & \\
\hline $\mathrm{AB}$ & 4.37 & 1 & 4.37 & 3.27 & 0.1006 & \\
\hline BC & 15.26 & 1 & 15.26 & 11.43 & 0.0070 & \\
\hline $\mathrm{B}^{2}$ & 21.46 & 1 & 21.46 & 16.07 & 0.0025 & \\
\hline $\mathrm{C}^{2}$ & 16.88 & 1 & 16.88 & 12.64 & 0.0052 & \\
\hline $\mathrm{ABC}$ & 16.29 & 1 & 16.29 & 12.20 & 0.0058 & \\
\hline $\mathrm{A}^{2} \mathrm{C}$ & 92.96 & 1 & 92.96 & 69.61 & 0.0001 & \\
\hline $\mathrm{AB}^{2}$ & 43.48 & 1 & 43.48 & 32.56 & 0.0002 & \\
\hline $\mathrm{AC}^{2}$ & 0.000 & 0 & & & & \\
\hline $\mathrm{B}^{2} \mathrm{C}$ & 0.000 & 0 & & & & \\
\hline $\mathrm{A}^{3}$ & 0.000 & 0 & & & & \\
\hline $\mathrm{C}^{3}$ & 0.000 & 0 & & & & \\
\hline Residual & 13.36 & 10 & 1.34 & & & \\
\hline Lack of Fit & 12.95 & 5 & 2.59 & 32.09 & 0.0008 & significant \\
\hline Pure Error & 0.40 & 5 & 0.081 & & & \\
\hline Cor Total & 304.65 & 19 & & & & \\
\hline Model & 291.29 & 9 & 32.37 & 24.23 & 0.0001 & significant \\
\hline A-temperature & 55.33 & 1 & 55.33 & 41.43 & 0.0001 & \\
\hline C-Reaction time & 102.79 & 1 & 102.79 & 76.96 & 0.0001 & \\
\hline
\end{tabular}

\subsection{ANOVA}

ANOVA is a statistical method used for the hypotheses testing on the model parameters in which the total variation in a set of data was divided into various components associated with specific sources. The ANOVA represent whether the equation of regression sufficiently indicates the association with the significant and response variables. In ANOVA, mean squares are calculated by sum of squares division by degrees of freedom, while the sum of squares is used to evaluate the square of deviation from the grand mean. The ANOVA of such models represents that the highly significant models, as it is obvious from the $\mathrm{F}$ value $(24.23)$, probability value $(\mathrm{P}<0.05)$. The model is significant statistically, when the $\mathrm{P}$ value is less than 0.05. These results are tabulated in Table 5. The residual error term in ANOVA is the measurement of the variation amount in the missing of unexplained response data by the model. In data analysis method, the misleading outcomes are evaluated by using the validation techniques. By calculating the final equation the insignificant parameters are removed and significant parameters only considered. The final equation related with coded factors is represented below:

$$
\begin{aligned}
& \text { Adsorption capacity }=22.04+5.26 \mathrm{~A}+7.17 \mathrm{C}+0.74 \mathrm{AB}-1.38 \mathrm{BC}-2.59 \mathrm{~B}^{2}-2.30 \mathrm{C}^{2}+1.43 \mathrm{ABC} \\
& -7.62 \mathrm{~A}^{2} \mathrm{C}-5.21 \mathrm{AB}^{2}+\mathrm{AC}^{2}+\mathrm{B}^{2} \mathrm{C}+\mathrm{A}^{3}+\mathrm{C}^{3}
\end{aligned}
$$

In table 5 , the activation temperature, activation time and $\mathrm{IR}$ indicated $\mathrm{MB}$ adsorption significant effects. Fig. 11 demonstrates the variety in the adsorption capacity of AC by varying the activation time and activation temperature in the type of lines and 3D surface are plotted. The adsorption capacity increases with raise in the temperature from $400-700{ }^{\circ} \mathrm{C}$, in which the adsorption capacity variation plotted against to time of reaction is low considerable due to low changes in the adsorption capacity [1]. For example, when the reaction time at maximum $120 \mathrm{~min}$ the adsorption capacity is only shown 14 $\mu \mathrm{g} / \mathrm{mg}$. All in all, the MB adsorption capacity it is not just contingent upon physical attributes of porous carbon, its depending in compound chemical nature as well. During maximum times of activation, the modification (quantity and quality) in function groups may thereafter change the MB adsorption space.

Fig. 13 represents the effect of IR and activation temperature on the capacity of adsorption 3D surface plot and Fig. 14 demonstrates response of $3 \mathrm{D}$ surface plot of the result of activation time and IR on adsorption capacity. The adsorption capacity indicates an increase run with the raise in activation temperature and IR. The maximum capacity of adsorption was obtained when the two variables temperature and IR had maximum values during the studied range. An increase in MB adsorption capacity shows the raise in pore size suitability to conciliate the molecules of MB. Estimations on the raise in adsorption capacity of $\mathrm{MB}$ with rise in the $\mathrm{IR}$ and activation temperature.

They obtained when an improvement in IR and activation temperature, that results the significant increase in the MB adsorption capacity. The porosity improvement occurs because of the new pores creation or to exiting pores enlargement. Additionally, show the variation in adsorption capacity with respect to time of activation is low considerable at maximum IR as match up to the minimum IR. The ANOVA results indicate activation temperature and IR to be considerable parameters, while activation 
time was found to be marginal on the adsorption space. Fig. 12 represents the relationship between the predicted adsorption capacities against the investigational (actual) adsorption capacity of ACSH. As shown, the expected results similar very well with the experimental results, show the successful capability of the model to captivate the association with the variables used for the operation and adsorption capacity of ACSH.

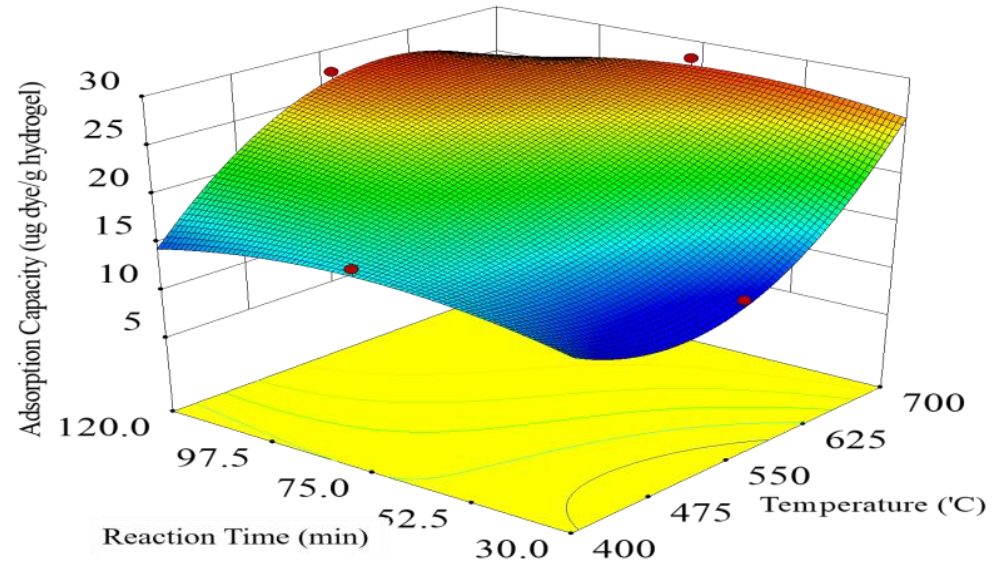

Fig. $113 D$-surface plot of IR and activation time on adsorption capacity.

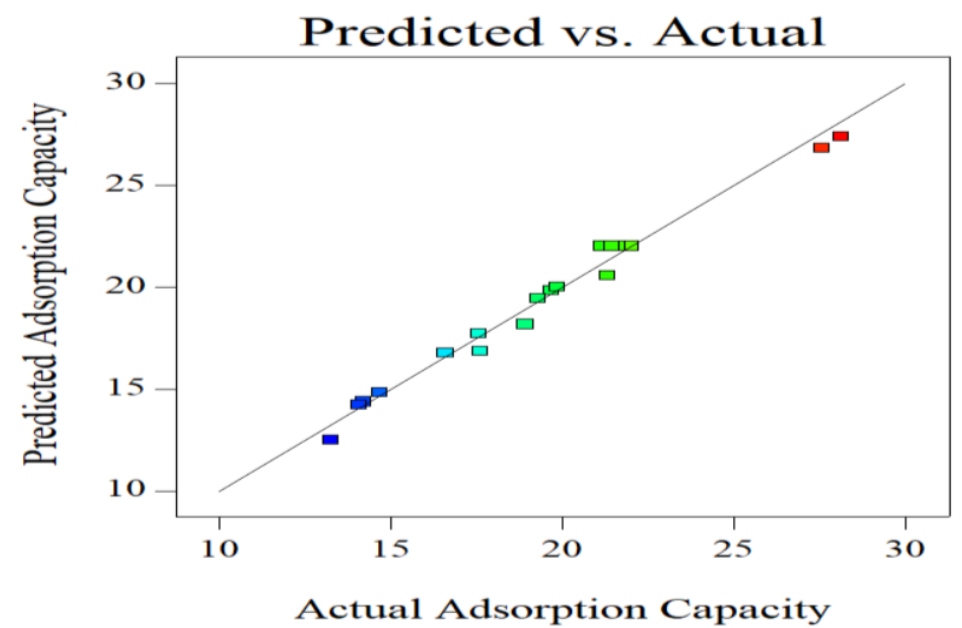

Fig. 12 Predicted adsorption capacity versus actual adsorption capacity.

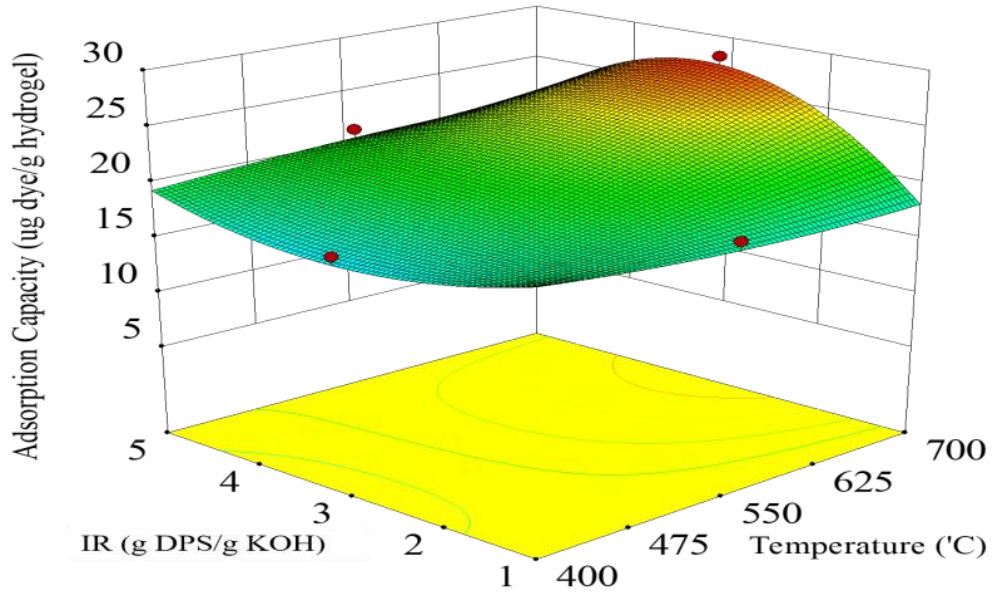

Fig. 13 3D-surface plot of IR and activation 


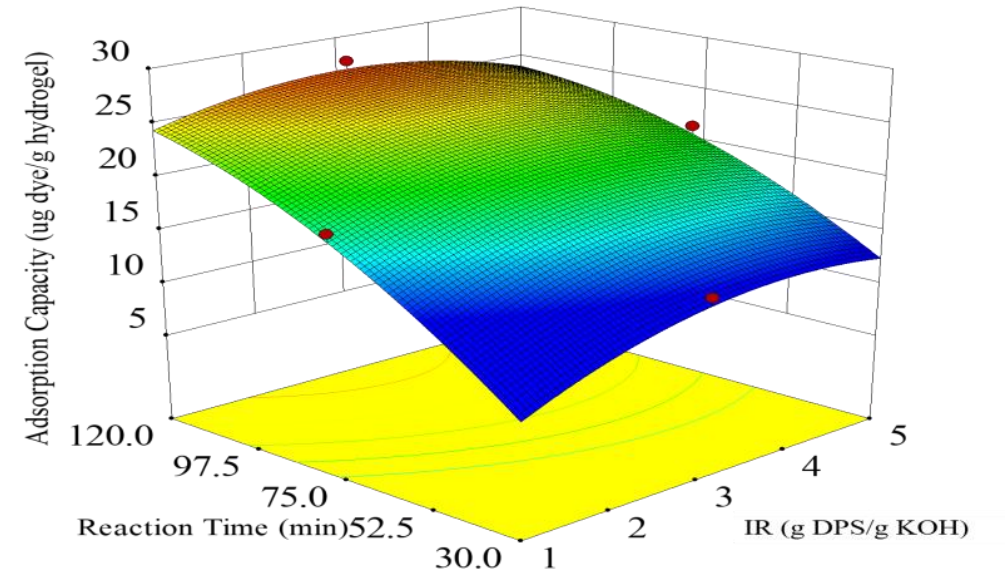

Fig. $143 D$-surface plot of IR and activation time on adsorption capacity.

\subsection{SEM of Date Seeds Raw}

The surface morphology of raw date seeds powder by SEM is shown in Fig. 15 the images were taken in various scales to illustrate the date seeds powder more obvious. SEM images of date seeds powder before activation showed an absence of pores.

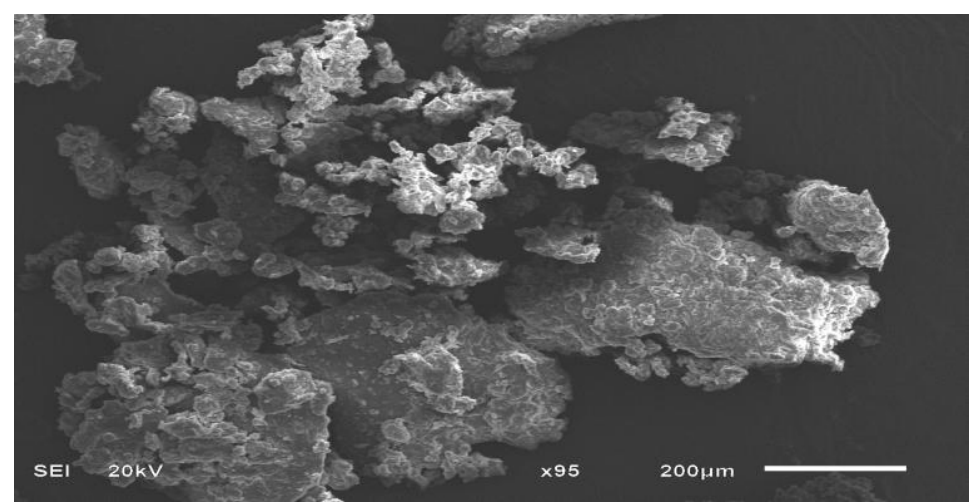

Fig. 15 High maginfication SEM image of raw date seeds powder

\subsection{SEM of Activated and Carbonized Date Seeds}

Fig. 16 Shows a high magnification images of date seeds after activation.

SEM confirms presence of highly microporous in various sizes on the surface of the carbon. All the bonds are broken and more crystallized carbon slaps cut off to make SP2 and SP3 groups. (a) Shows before washing the activated sample with HCL and (b) after washing the sample with HCL. After washing, all the ashes were removed more and clean pores can visible to show the improvement in morphology of surface and roughness.
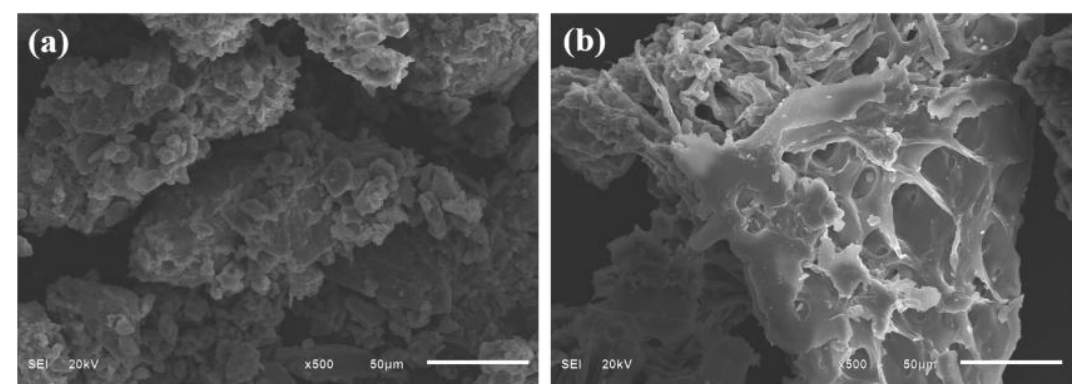

Fig. 16 High maginification image of AC (a) shows before washing the activated sample with HCL and (b) after washing the sample with HCL.

\subsection{SEM of AC at Various Activation Temperatures}

17 displays high magnification of $\mathrm{AC}$ images at various temperatures of activation (a) at low heat $400{ }^{\circ} \mathrm{C}$, (b) at $550{ }^{\circ} \mathrm{C}$ and (c) at maximum heat $700{ }^{\circ} \mathrm{C}$. SEM image shows more presence of porous at high temperature with less potassium residues, while at low temperature $400 \mathrm{C}$ more potassium resides were 
found in EDS. To summarize this, a raise in the activation temperature contribute to rise of number of carbon pores which gives maximum capacity of adsorption and maximum area of surface.
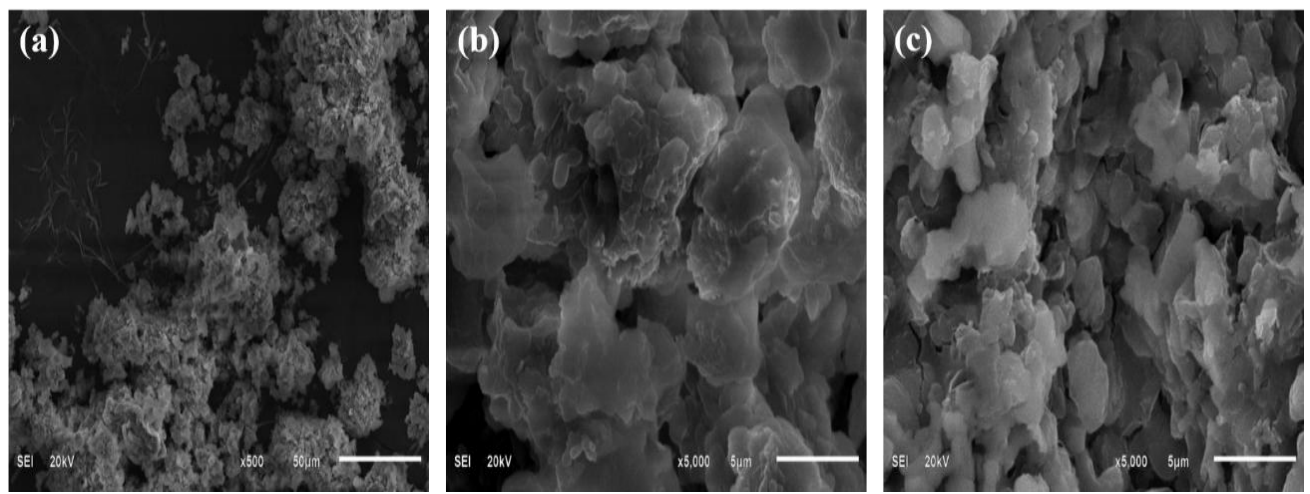

Fig. 17 SEM image of $A C$ at various activation temperatures (a) $400{ }^{\circ} \mathrm{C}$, (b) $550{ }^{\circ} \mathrm{C}$ and (c) $700{ }^{\circ} \mathrm{C}$.

\subsection{SEM of AC at Different IR}

Fig. 18 and Fig. 19 revels the morphology of the AC at various IRs Fig. 18 at IR 1 and Fig. 19 at IR 5. SEM image shows more presence of porous at high IR compared to low IR. The SEM images confirm an improvement in the IR ratio and time of activation contributed to increase the number of porous carbon and roughness of the surface.

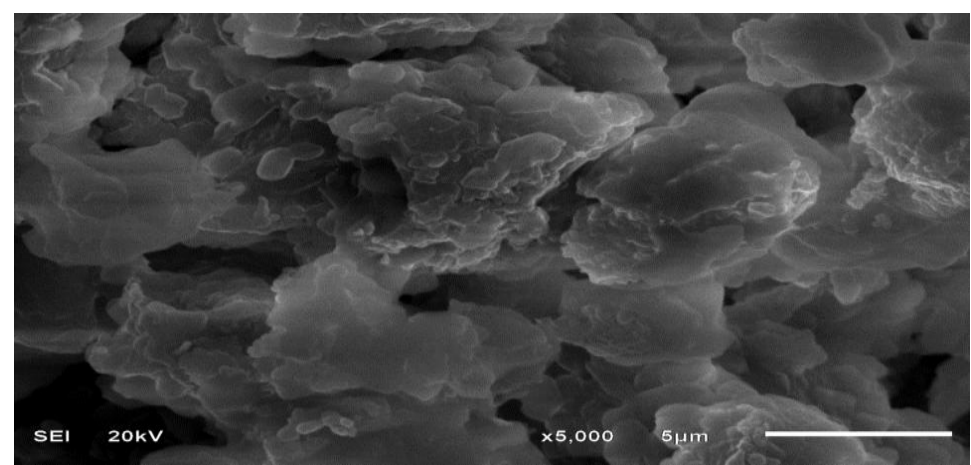

Fig. 18 SEM AC image at IR=1.

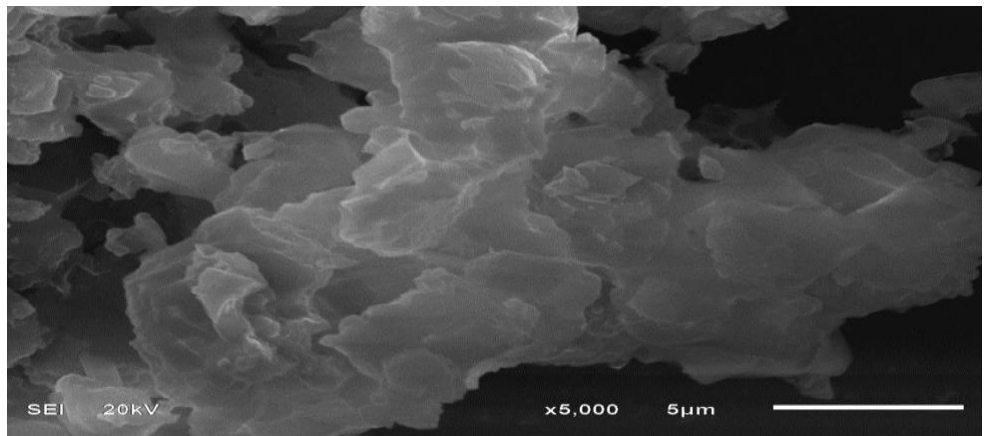

Fig. 19 SEM AC image at $I R=5$.

\section{Conclusion}

AC achieved a satisfactory adsorption performance and it is a new adsorbent starch AC hydrogel arranged by a simple operation from low cost adsorbents obtained from Omani bio wastes material. In this study we found $28.13 \mu \mathrm{g}$ of dye/g of adsorbent which was $225 \%$ enhancement compared to that of the plain starch hydrogel. The experimental optimum conditions were found to be an activation time $58 \mathrm{~min}$, activation temperature of $400^{\circ} \mathrm{C}$ and IR of 3. The SEM, for their morphology, and UV-Vis for their use perspectives, confirmed that the ACSH will open a new era to the world for better and safer water. The results of ANOVA indicate that the IR and temperature of activation to be the parameters of significant, while time of activation was observed to be minor on the capacity of adsorption. The experimental data on the kinetics study of adsorption of MB on ACSH was observed that pseudo first order sample better explained the kinetics data for MB adsorption which indicates that the interaction is more inclined 
towards physisorprion. The model suitable for the experimental data is Freundlich, which is superior to Langmuir. The possible mechanisms of adsorption are mainly due to hydrogen bonding and $\Pi-\Pi$ stacking interactions with the species of hydrogels. Finally, the procedure applied in the present study can be modified and optimized for a larger scale of adsorbing water contaminants.

\section{Compliance with Ethical Standards}

Conflicts of interest: Authors declared that they have no conflict of interest.

Human participants: The conducted research follows the ethical standards and the authors ensured that they have not conducted any studies with human participants or animals.

\section{References}

[1] adsorption technology. Nature protocols, 2006. 1(6): p. 2661.

[2] Al-Shahib, W. and Marshall, R.J., 2003. The fruit of the date palm: its possible use as the best food for the future. International journal of food sciences.

[3] Banat, F., Al-Asheh, S. and Al-Makhadmeh, L., 2003. Evaluation of the use of raw and activated date pits as potential adsorbents for dye containing waters. Process Biochemistry, 39(2), pp.193-202.

[4] Bautista-Toledo, I., Ferro-Garcia, M.A., Rivera-Utrilla, J., Moreno-Castilla, C. and Vegas Fernández, F.J., 2005. Bisphenol A removal from water by activated carbon. Effects of carbon characteristics and solution chemistry. Environmental science \& technology, 39(16), pp.6246-6250.

[5] Cheng, S., et al., Characterisation and application of a novel positively charged nanofiltration membrane for the treatment of textile industry wastewaters. 2012. 46(1): p. 33-42.

[6] Das, R., et al. (2014). "Carbon nanotube membranes for water purification: a bright future in water desalination." Desalination 336: 97-109.

[7] D, Müller, M. B., Gilje, S., Kaner, R. B., \& Wallace, G. G. (2008). Processable aqueous dispersions of graphene nanosheets. Nature Nanotechnology. vol. 3, pp. 101.

[8] Dyson T (1996) Population and food: global trends and future prospects. Routledge, London.

[9] Foo, K.Y. and Hameed, B.H., 2011. Utilization of rice husks as a feedstock for preparation of activated carbon by microwave induced KOH and K2CO3 activation. Bioresource Technology, 102(20), pp.9814-9817.

[10] Fu, F. and Q. Wang (2011). 'Removal of heavy metal ions from wastewaters: a review.' Journal of environmental management 92(3): 407-418.

[11] Gopal, K., et al. (2007). 'Chlorination byproducts, their toxicodynamics and removal from drinking water.' Journal of hazardous materials 140(1-2): 1-6.

[12] Gupta, V.K., Gupta, B., Rastogi, A., Agarwal, S. and Nayak, A., 2011. A comparative investigation on adsorption performances of mesoporous activated carbon prepared from waste rubber tire and activated carbon for a hazardous azo dye-Acid Blue 113. Journal of Hazardous Materials.

[13] Gupta, V.K., Gupta, B., Rastogi, A., Agarwal, S. and Nayak, A., 2011. A comparative investigation on adsorption performances of mesoporous activated carbon prepared from waste rubber tire and activated carbon for a hazardous azo dye-Acid Blue 113. Journal of Hazardous Materials.

[14] Hameed, B.H. and Rahman, A.A., 2008. Removal of phenol from aqueous solutions by adsorption onto activated carbon prepared from biomass material. Journal of hazardous materials.

[15] Hameed, B.H., Din, A.M. and Ahmad, A.L., 2007. Adsorption of methylene blue onto bamboo-based activated carbon: kinetics and equilibrium studies. Journal of hazardous materials, 141(3), pp.819-825.

[16] Hayashi, J.I., Kazehaya, A., Muroyama, K. and Watkinson, A.P., 2000. Preparation of activated carbon from lignin by chemical activation. Carbon, 38(13), pp.1873-1878.

[17] Huang, C.B., et al., Production, characterization, and mechanical properties of starch modified by Ophiostoma spp. BioResources, 2007. 1(2): p. 257-269.

[18] Hummer, G., Rasaiah, J. C. and Noworyta, J. P. (2001) 'Water conduction through the hydrophobic channel of a carbon nanotube', Nature, 414(6860), pp. 188.

[19] Ismail, H., et al. (2013). "Starch-based hydrogels: present status and applications." International Journal of Polymeric Materials and Polymeric Biomaterials 62(7): 411-420.

[20] Jamil, F., Ala'a, H., Naushad, M., Baawain, M., Al-Mamun, A., Saxena, S. K. and Viswanadham, N. (2017) 'Evaluation of synthesized green carbon catalyst from waste date pits for tertiary butylation of phenol', Arabian Journal of Chemistry.

[21] Jiao, T., et al. (2015). "Self-assembly reduced graphene oxide nanosheet hydrogel fabrication by anchorage of chitosan/silver and its potential.

[22] Karakoti, M., Dhali, S., Rana, S., Prasanna, S. R. V. S., Mehta, S. and Sahoo, N. G. (2018) 'Surface Modification of Carbon-Based Nanomaterials for Polymer Nanocomposites',Carbon-Based Polymer Nanocomposites for Environmental and Energy Applications: Elsevier, pp. 27-56.

[23] Kar, B., et al., Investigations on different starches as depressants for iron ore flotation. Minerals Engineering, 2013. 49: p. 1-6.

[24] Kinniburgh, D.G., 1986. General purpose adsorption isotherms. Environmental Science \& Technology, 20(9), pp.895-904. 
[25] Kizil, R., J. Irudayaraj, and K. Seetharaman, Characterization of irradiated starches by using FT-Raman and FTIR spectroscopy. Journal of agricultural and food chemistry, 2002. 50(14): p. 3912-3918.

[26] Konicki, W., et al., Adsorption of anionic azo-dyes from aqueous solutions onto graphene oxide: equilibrium, kinetic and thermodynamic studies. Journal of colloid and interface science, 2017. 496: p. 188-200.

[27] Lanthong, P., R. Nuisin, and S. Kiatkamjornwong, Graft copolymerization, characterization, and degradation of cassava starch-g-acrylamide/itaconic acid superabsorbents. Carbohydrate Polymers, 2006

[28] Liu, M., Dong, F., Zhang, W., Nie, X., Wei, H., Sun, S., Zhong, X., Liu, Y. and Wang, D. (2017) 'Contribution of surface functional groups and interface interaction to biosorption of strontium ions by Saccharomyces cerevisiae under culture conditions', RSC Advances.

[29] Li, Y., et al., Facile synthesis of Fe3O4 nanoparticles decorated on 3D graphene aerogels as broad-spectrum sorbents for water treatment. Applied Surface Science, 2016. 369: p. 11-18.

[30] Lozano-Castello, D., Lillo-Rodenas, M.A., Cazorla-Amorós, D. and Linares-Solano, A., 2001. Preparation of activated carbons from Spanish anthracite: I. Activation by KOH. Carbon, 39(5), pp.741-749.

[31] Lozano-Castello, D., Lillo-Rodenas, M.A., Cazorla-Amorós, D. and Linares-Solano, A., 2001. Preparation of activated carbons from Spanish anthracite: I. Activation by KOH. Carbon, 39(5), pp.741-749.

[32] Mangun, C.L., Benak, K.R., Economy, J. and Foster, K.L., 2001. Surface chemistry, pore sizes and adsorption properties of activated carbon fibers and precursors treated with ammonia. Carbon.

[33] Meng, J., et al., Adsorption capacity of kelp-like electrospun nanofibers immobilized with bayberry tannin for uranium (vi) extraction from seawater. RSC Advances, 2019. 9(14): p. 8091-8103.

[34] Merakchi, A., et al., Cross-linking and modification of sodium alginate biopolymer for dye removal in aqueous solution. Polymer Bulletin, 2018: p. 1-20.

[35] D. C. (2012). Design and Analysis of Experiments, 8th Edition: Wiley.Rigas, F., Dritsa, V., Marchant, R., Papadopoulou, K., Avramides, E. J., \& Hatzianestis,.

[36] Nakajima, T., A. Mabuchi, and R. Hagiwara, A new structure model of graphite oxide. Carbon, 1988. 26(3): p. 357-361.

[37] Naushad, M., et al., Synthesis and characterization of a new starch/SnO2 nanocomposite for efficient adsorption of toxic Hg2+ metal ion. Chemical Engineering Journal, 2016. 300: p. 306-316.

[38] Nolan, Galadima, kucherova, A.E., Agarwal, S., Tkachev, A.G. and Gupta, V.K 2010. Adsorption of heavy metals on conventional and nanostructured materials for wastewater treatment purposes: A review. Ecotoxicology and environmental safety, 148, pp.702-712.

[39] Ramesha, G., et al., Graphene and graphene oxide as effective adsorbents toward anionic and cationic dyes. Journal of colloid and interface science, 2011. 361(1): p. 270-277.

[40] Pourjavadi, A., et al., Preparation of porous graphene oxide/hydrogel nanocomposites and their ability for efficient adsorption of methylene blue. 2016. 6(13): p. 10430-10437.

[41] Pyrzyńska K, Bystrzejewski M. (2010) Comparative study of heavy metal ions sorption onto activated carbon, carbon nanotubes, and carbon-encapsulated magnetic nanoparticles. Colloids and Surfaces A: Physicochemical and Engineering Aspects, 362(1-3):102-9.

[42] Qiu, J., Xu, L., Peng, J., Zhai, M., Zhao, L., Li, J. and Wei, G., 2007. Effect of activated carbon on the properties of carboxymethylcellulose/activated carbon hybrid hydrogels synthesized by Y-radiation technique. Carbohydrate polymers, 70(2), pp.236-242.

[43] Reddy, D., et al. (2015). Preparation of activated carbons from bio-waste: effect of surface functional groups on methylene blue adsorption.

[44] Schröder, E., et al. (2007). "Experiments on the generation of activated carbon from biomass." Journal of analytical and applied pyrolysis 79(1-2): 106-111.

[45] Schröder, E., Thomauske, K., Weber, C., Hornung, A. and Tumiatti, V., 2007. Experiments on the generation of activated carbon from biomass. Journal of analytical and applied pyrolysis, 79(1-2), pp.106-111.

[46] Sekar, M., Sakthi, V. and Rengaraj, S., 2004. Kinetics and equilibrium adsorption study of lead (II) onto activated carbon prepared from coconut shell. Journal of colloid and interface science, 279(2), pp.307-313.

[47] Suh, M.-J., et al., Titanium Dioxide-Layered Double Hydroxide Composite Material for AdsorptionPhotocatalysis of Water Pollutants. Langmuir, 2019.

[48] Sundaram, J., T.D. Durance, and R. Wang, Porous scaffold of gelatin-starch with nanohydroxyapatite composite processed via novel microwave vacuum drying. Acta biomaterialia, 2008. 4(4): p. 932-942.

[49] Solairaj, D., et al. (2015). Adsorption of Methylene Blue, Bromophenol Blue and Coomassie Brilliant Blue by aChitin Nanoparticles.

[50] Su, C. and K.P. Loh, Carbocatalysts: graphene oxide and its derivatives. Accounts of chemical research, 2012. 46(10): p. 2275-2285.

[51] Srivastava, V.C., Swamy, M.M., Mall, I.D., Prasad, B. and Mishra, I.M., 2006. Adsorptive removal of phenol by bagasse fly ash and activated carbon: equilibrium, kinetics and thermodynamics. Colloids and surfaces a: physicochemical and engineering aspects, 272(1-2), pp.89-104.

[52] Tan, I.A.W., Hameed, B.H. and Ahmad, A.L., 2007. Equilibrium and kinetic studies on basic dye adsorption by oil palm fibre activated carbon. Chemical Engineering Journal, 127(1-3), pp.111-119.

[53] Tay, T., et al. (2009). "Preparation and characterization of activated carbon from waste biomass." Journal of hazardous materials 165(1-3): 481-485.

[54] Terranova, M. L., et al. (2006). "The world of carbon nanotubes: an overview of CVD growth methodologies." Chemical Vapor Deposition 12(6): 315-325. 
[55] Upadhyayula, V. K., Deng, S., Mitchell, M. C. and Smith, G. B. (2009) 'Application of carbon nanotube technology for removal of contaminants in drinking water: a review', Science of the total environment, 408(1), pp. $1-13$

[56] Wang, Z., et al., Effective desalination by capacitive deionization with functional graphene nanocomposite as novel electrode material. 2012. 299: p. 96-102.

[57] Wu, Z.-S., et al., Anchoring Hydrous RuO2 on Graphene Sheets for High-Performance Electrochemical Capacitors. Advanced Functional Materials, 2010. 20(20): p. 3595-3602.

[58] Yang, K., J. Wang, and B. Chen, Facile fabrication of stable monolayer and few-layer graphene nanosheets as superior sorbents for persistent aromatic pollutant management in water. Journal of Materials Chemistry A, 2014. 2(43): p. 18219-18224.

[59] Yang, W.L., et al., Hydrothermal synthesis of reduced graphene sheets/Fe2O3 nanorods composites and their enhanced electrochemical performance for supercapacitors. Solid State Sciences, 2013. 20: p. 46-53.

[60] Zhang, P., et al., One-Step Synthesis of Large-Scale Graphene Film Doped with Gold Nanoparticles at LiquidAir Interface for Electrochemistry and Raman Detection Applications. Langmuir, 2014. 30(29): p. 8980. 